\title{
Keyframe or Motion Capture? Reflections on Education of Character Animation
}

\author{
Tsai-Yun Mou ${ }^{1 \star}$ \\ ${ }^{1}$ National Pingtung University, TAIWAN
}

Received 20 April 2018 • Revised 12 August 2018 - Accepted 13 September 2018

\begin{abstract}
In character animation education, the training process needs diverse domain knowledge to be covered in order to develop students with good animation ability. However, design of motion also requires digital ability, creativity and motion knowledge. Moreover, there are gaps between animation education and industry production which motion capture is widely applied. Here we try to incorporate motion capture into education and investigate whether motion capture is supportive in character animation, especially in creativity element. By comparing two kinds of motion design method, traditional keyframe and motion capture, we investigated students' creativity in motion design. The results showed that in originality factor, keyframe method had slightly higher performance support for designing unusual motions. Nevertheless, motion capture had shown more support in creating valid actions in quantity which implied fluency factor of creativity was achieved. However, in flexibility factor, although motion capture created more emotions in amount, keyframe method actually offered higher proportion of sentiment design. Participants indicated that keyframe was helpful to design extreme poses. While motion capture provided intuitive design tool for exploring possibilities. Therefore, we propose to combine motion capture technology with keyframe method in character animation education to increase digital ability, stimulate creativity, and establish solid motion knowledge.
\end{abstract}

Keywords: animation education, character animation, creativity, motion capture, virtual character

\section{INTRODUCTION}

The education of animation is a long-standing and multidisciplinary training. Since in animation production it involves various stages of creation, from script writing, storyboard, layout and art design in pre-production stage, to modeling, 2D or 3D character animation, color/texture, and lighting in production stage, and finally the postproduction stage of special effects, compositing and sounds. These different phases of production constitute a complex but creative work chain that cannot be accomplished without contributions from each part. Nowadays, with the assistance of technology, such as motion capture, virtual reality, computer simulation, or other intuitive interactive equipment, etc., are widely used in actual productions as well to support artists' need in their creation process. We can see that almost in every film, whether animation or live action, utilizes plenty technology in achieving astonishing and amazing experiences for the audience. In other words, to create believable animation, taking advantage of the technology assistance is current trend and it is necessary in animation industry.

Nevertheless, looking back into animation education in college, there seems to be less connection between art and technology until now. Animation training has to cover wide range in the creative part, such as story design, character design, and animation design (Mou \& Tu, 2013). It is through these different aspects of animation training that students express their ideas with their artistic skills. Besides traditional animation-focused training, to further master particular profession, for example, character animation, knowledge of anatomy, physics, and even psychology is also very important. Since character animation is the 'acting' of virtual character, it is crucial to have

(c) 2018 by the authors; licensee Modestum Ltd., UK. This article is an open access article distributed under the terms and conditions of the Creative Commons Attribution License (http://creativecommons.org/licenses/by/4.0/). \tmou@mail.nptu.edu.tw (*Correspondence) 


\section{Contribution of this paper to the literature}

- Incorporating motion capture technology into animation education is feasible and effective.

- Combination of traditional keyframe technique and motion capture technology can enhance students' sense of animation timing, acting, aesthetics, digital ability and creativity.

- Teachers in animation field can adopt proper digital tools to assist their teaching for better learning outcomes. Motion capture can be a great tool for character animation design.

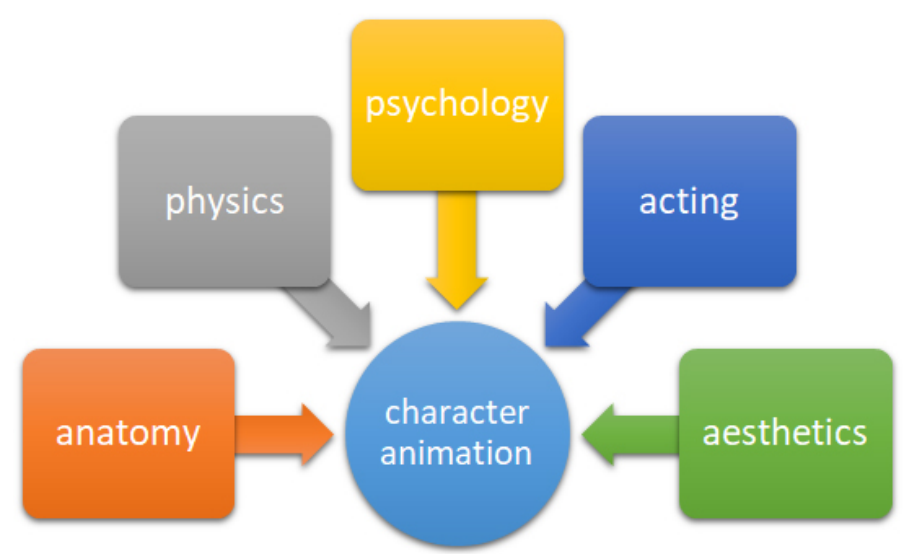

Figure 1. Character animation learning is transdisciplinary

knowledge of anatomy in order to present proper body structure and muscles. The motions also have to follow rules of physics, so the movement can be smooth and believable. Moreover, to revel the emotions of virtual characters with appropriate facial expressions, body postures, and timing, it is also very helpful to have knowledge of psychology, so the performance could be convincing and appealing. From the example of character animation above, we can understand that to achieve certain level of specialty in animation, there is not only particular training in one field, but also related knowledge to build up the ability. In other words, character animation learning is transdisciplinary. This concept is corresponding with the STEAM trend in education, which science, technology, engineering, art, and mathematics knowledge and skills are mixed and learned together for complete education (Costantino, 2017; Liao, 2016; Riley, 2012). Figure 1 shows the concept of character animation learning that integrates different knowledge domains.

The differences between animation school education and animation industry are thus obvious. Although in animation education computer skill courses are included in the curriculum, this does not mean art and technology are in combination with each other. Computer animation courses in college are more like instructional learning which teachers instruct functionality of software. Students although create works with certain software, in many cases the digital art works could not reveal their creativity because lack of tool proficiency. In my teaching experiences of more than 10 years in 3D animation, many students are frustrated by complex interface and even lost their interests in creating animation because of difficulties in software. Figure 2 shows an example of the interface of MAYA 3D animation software that is used by industry and most computer animation courses. Moreover, animation fundamental training and computer skills training are separated courses; not to mention the actual teaching content of computer animation is software functionality. Therefore, there are few connections between art expression and technology support in current college education.

Having the notion of this kind of education situation, this paper would focus on the 'animation' part, especially character animation, to analyze the facts of traditional animation training in college and propose a new teaching approach to improve the situation. An exploratory research was conducted to verify the feasibility of using motion capture technology in animation class. Moreover, this study would also look into the characteristics of current film/animation production and compare the differences and gaps between animation education and animation industry. The analysis could bring educators to rethink what should be the focus of character animation education and hopefully to make some contributions to animation teaching method. 


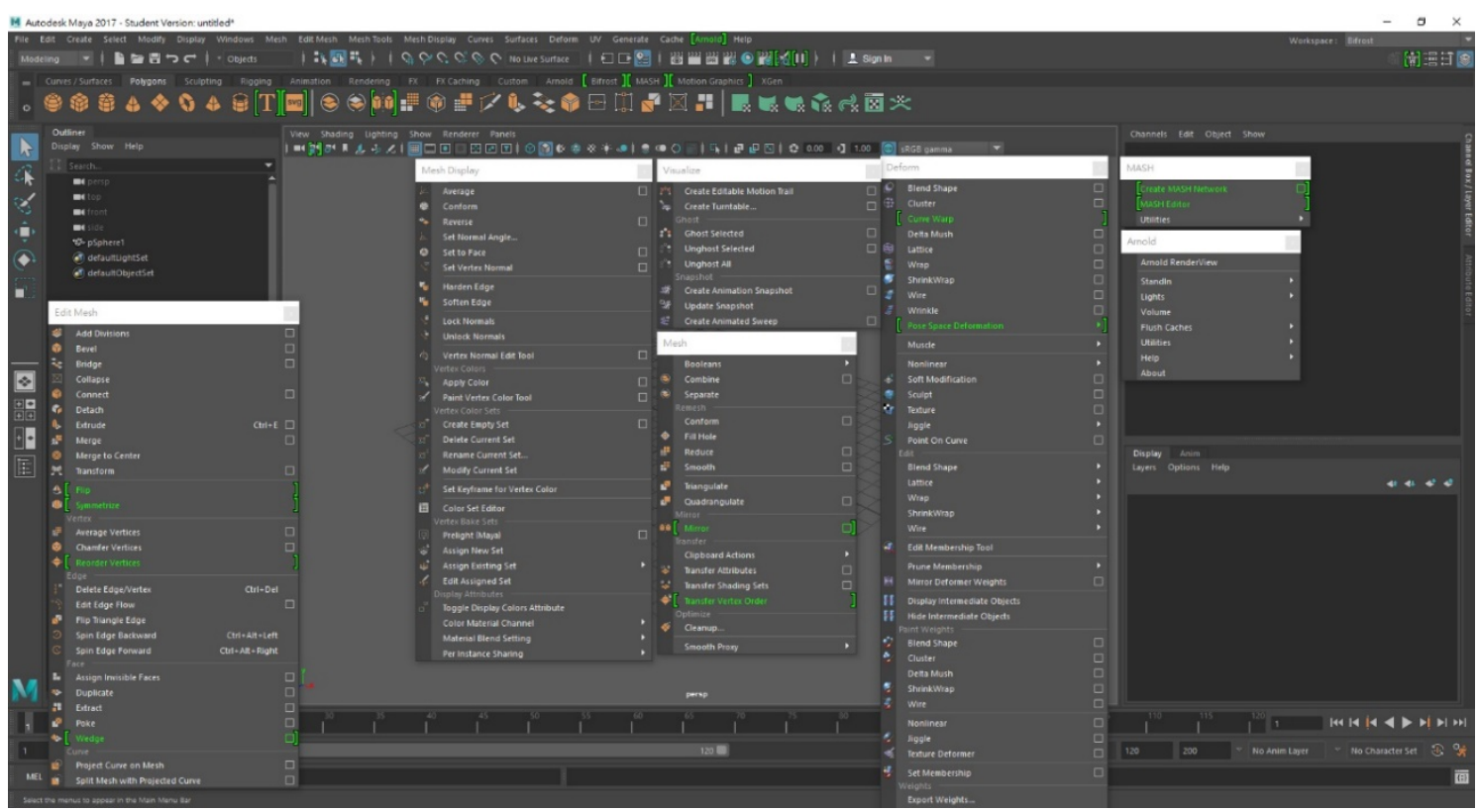

Figure 2. Interface of MAYA

\section{Traditional Character Animation Training}

We could say that the development of character animation was set by Disney's Nine Old Men (Deja, 2015). They are the animators who created some of Disney's most famous cartoons, such as Snow White and the Seven Dwarfs, Pinocchio, and Sleeping Beauty. The Nine Old Men also refined well-known '12 principles of animation' (Johnston \& Thomas, 1981), which almost all animators and animation educators would regard the principles as working bible. These principles are applied to both 2D and 3D animation because they are fundamental concepts of motion and aesthetics that would contribute to the appealing of animation.

Richard William's book 'The Animator's Survival Kit' (Williams, 2012) is another is another influential source that are widely adopted in animation education and industry. This book analyzes motion with each keyframe and shows every pose for learners to complete understanding. It focuses on character animation of various poses including human and animals. Therefore, the knowledge that this book contains is very useful and practical.

The other important training resource is Eadweard Muybridge's photography works. His pioneering work in photographic studies of motion are widely used as motion references in animation (Muybridge, 2012). The most well-known work is 'The Horse in Motion'. His later work 'Animals in Motion' and 'The Human Figure in Motion' are also regarded as significant materials for scientific studying of motion. These sequence of pictures are same concepts of animation keyframe. By observing real lives' motions, animators can analyze how human or animals move and how their muscles operate according to the movements. In other words, training of keen eyes is also important in character animation learning.

However, in many cases it is not always obtainable to have exact motion we need. When certain movements could not be found in books or videos, very often animators will act out and record the motion themselves for watching and analyzing. Video references performed by animators or others are quite common in animation production. By acting out particular motion, animators can try to capture the character's feeling, personality, and mood to reveal proper movement. That is why we also call animators are actors behind the scene. Richard Williams also mentioned this method in his book 'The Animator's Survival Kit'.

Even though with plenty of learning resources and methods, to expert in character animation, one still has to spend a lot of time in practicing animation, especially 2D hand-drawn animation. The learning and training period is quite long and still may not be able to achieve to a good enough level. Here 'good enough' we only refer to the fluency of animation, not how creative, appealing, or impressive of motion design.

From the discussion above, we can know that the training of character animation requires solid knowledge as well as sound practice in order to achieve good enough level. The learning resources although are plentiful, to transform knowledge into internal skills, one still has to spend plenty time on practicing. As we all know the saying 'learning by doing'. This fact applies to both 2D and 3D animation, and almost every profession. As for creativity of motion, this will depend on individual person, who constantly trains his/her eyes in observing movement, acts out possible or various motions and endeavors to create fluent animation. Thus, to become a good animator, not only professional skills are required, but also creativity in motion design is important. 


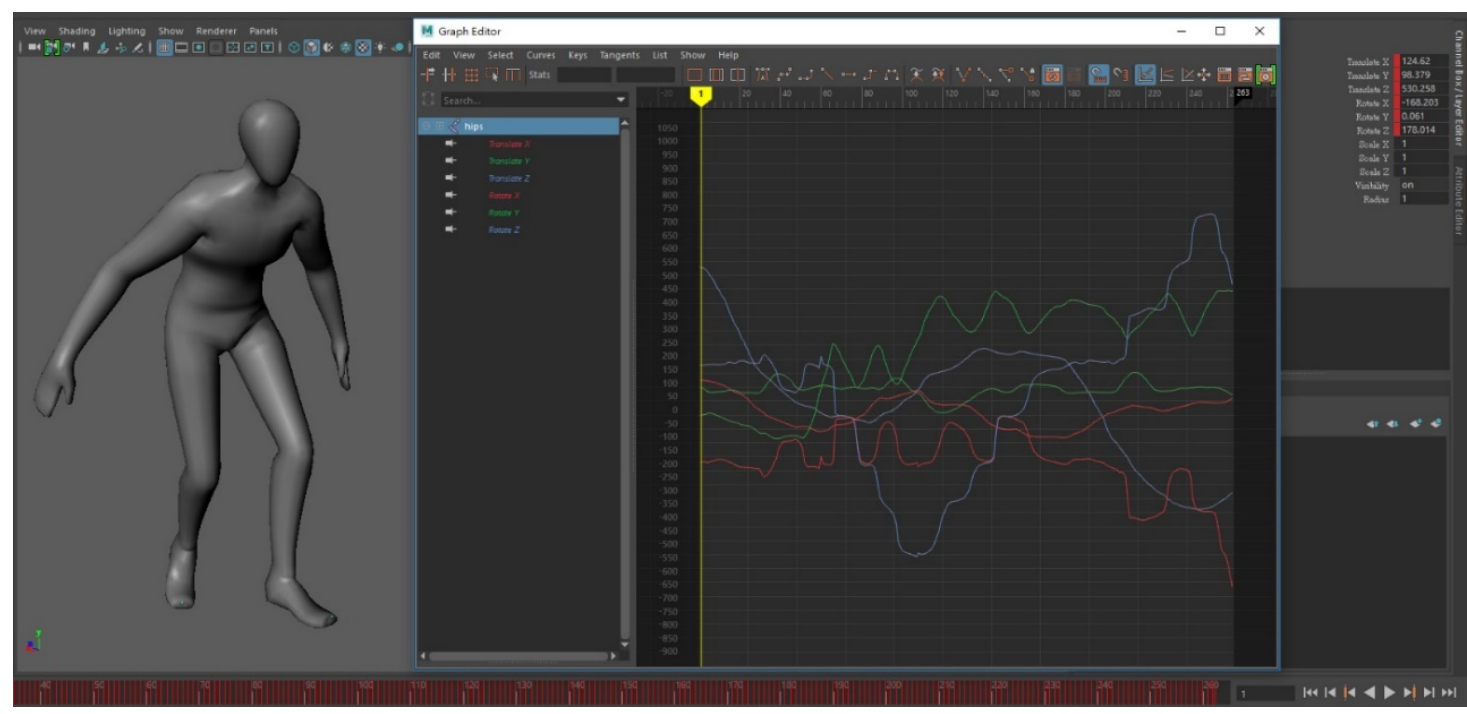

Figure 3. 3D motion revealed in digital numbers and curves

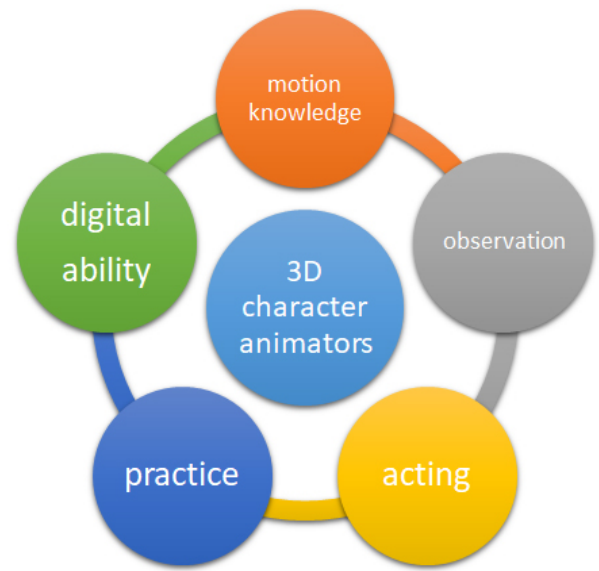

Figure 4. Requirements for 3D character animators

\section{D Computer Animation}

With the advance of technology, computer animation is taking its significant role in animation production and industry. Traditional hand-drawn 2D animation is thus gradually declining and 3D computer animation is growing. The first feature-length 3D computer animation 'Toy Story' (1995) by Pixar Animation Studios is pioneering in industry. From then on, Pixar and many other animation studios dedicated to develop and create amazing 3D animation to meet and even go beyond the audiences' expectation. The blooming of 3D computer animation grows in amount and progresses in visual. Computer generated images can save a lot of time in animation production; therefore, studios could create more new contents and release animations in each year. Also, with the software's features becoming more powerful, and with engineers' contributions to the extreme expressions of visual effects, compared with traditional hand-drawn animation, computer animations have become the dominant position.

Nevertheless, the prevailing status of computer animation does not mean the training of 3D computer animators could be easier than traditional animators. There are even more challenges to 3D animators. The complexity of software is the first issue. Animators have to learn how to use one or even more software in order to manipulate virtual characters with mouse and keyboard. Therefore, in many cases the display of motion is transformed to digit and curves. Figure 3 shows an example of 3D motion revealed in digital numbers and curves. This fact makes animation into 'computer algorithm' and animators have to train themselves to adjust to the creation and display of motion.

The second issue of exceling in 3D computer animation is same as traditional training, i.e., fundamental motion knowledge, good observation, acting, and lots of practice are all required. In other words, 3D animators have to be good at animating characters that reveal traditional knowledge, skills, and aesthetics with digital tools. Therefore, the demand for 3D animators is in fact much higher than traditional 2D animators. Figure 4 illustrates the requirements for $3 \mathrm{D}$ character animators. 


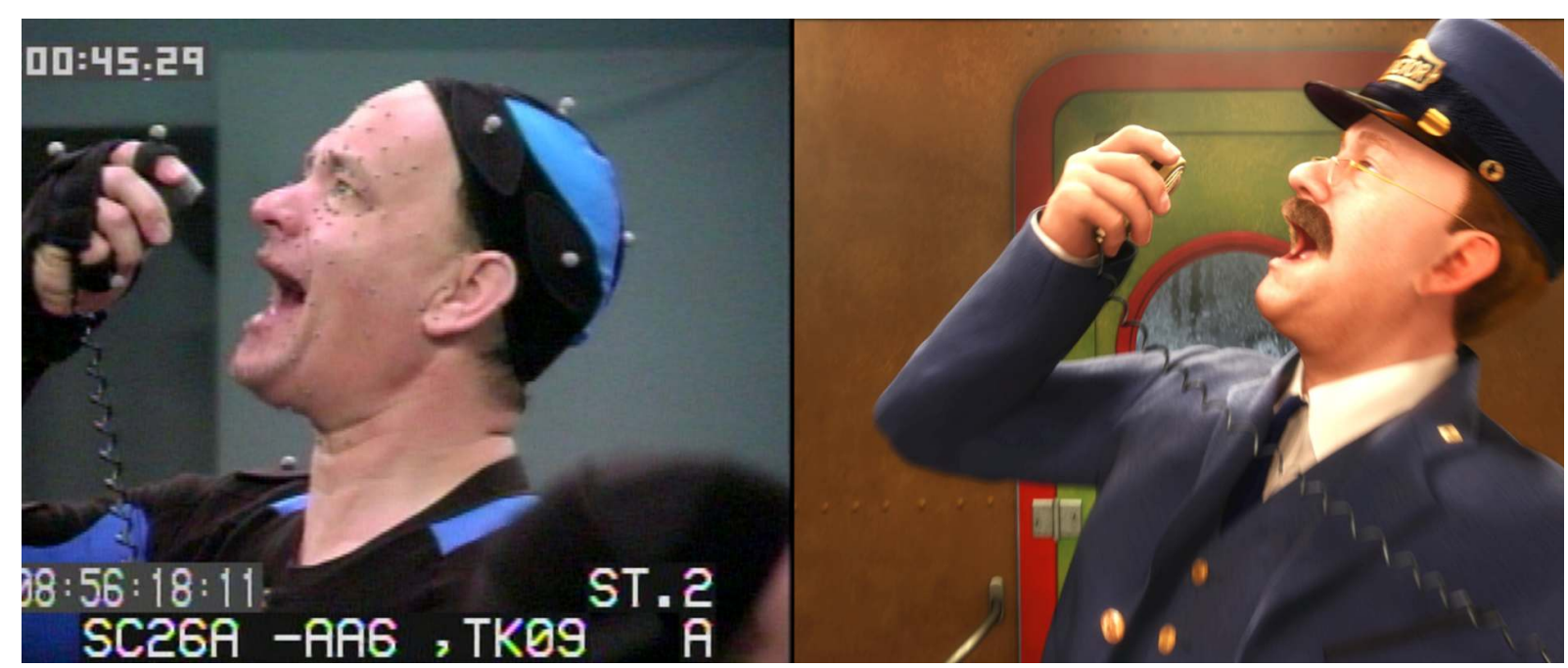

Figure 5. Tom Hanks' acting in 'The Polar Express' (2004)

(Image from Netflix Movies. https://www.netflixmovies.com)

\section{Motion Capture Technology}

Since the creation of 3D character animation is not simply computer generation, aesthetically appealing also takes an important role in its expression. It is essential for 3D artists to have solid animation knowledge and sense in order to convey the beauty of motion in virtual character. The evolution of technology also makes computer animation more friendly and accessible to animators. Integration of motion capture technology is the most striking practice in industry. Motion capture is the process of recording movement of objects or people. It is widely used in military, medical applications, sports, game, and film production. By recording live actions of human actors, the movement data can be applied to virtual characters (Dent, 2014). Therefore, actors play an active role for 3D characters and are important for the performance quality (Salomon, 2013). The strength of motion capture is its subtle expression. Motions like facial expressions or finger movement can be recorded, and this is often called as performance capture (Delbridge, 2016). The transfer of motion capture data to 3D virtual character is in fact similar to the traditional technique of 'rotoscope', which by tracing live-action footage frame-by-frame, the animated character can reproduce movements of actor. Similar idea is also presented in Eadweard Muybridge's photography work, in which he shot sequence of photos of human or animal movements. In other words, motion capture and rotoscope are simply a method or technique to create movement. The only difference between them is the technology.

Nowadays, the use of motion capture in film has become more and more often in production. However, in the early developmental stage, this technique received more critique than praise (Freedman, 2012). The pioneering work of mocap animation is Robert Zemeckis' 'The Polar Express' (Figure 5). This film used full captured facial and body motion of actors. The plot was based on a novel and generally had favorable reviews. However, the animation itself received negative criticism. The motion was said as 'lifeless' and 'creepy'. Indeed, from professional point of view, the motion in the film although is 'real', the lack of animated exaggeration makes the film appear 'fake'. The reason for this lies in the acting performance. Since real human movement is fluent and natural, if the actor does not consciously over perform, like traditional animation does, then the mocap result will appear dull and plain.

With the progress of motion capture technology, more animated films and feature films adopt this technique in their productions (Menache, 2010). For example, Robert Zemeckis' next animated film 'Monster House' (2006) was nominated Academy Award, Annie Award, and other awards. James Cameron's 'Avatar' (2009) which displayed photorealistic computer-generated characters used full body and facial motion capture (Figure 6). The film received positive reviews from audiences and compliments from filmmakers. Steven Spielberg even praised it as 'the most evocative and amazing science-fiction movie since Star Wars'. Nowadays the development of motion capture has become mature. Here we list systematically main feature films that utilized keyframe and motion capture technique in recent twelve years (Table 1). 


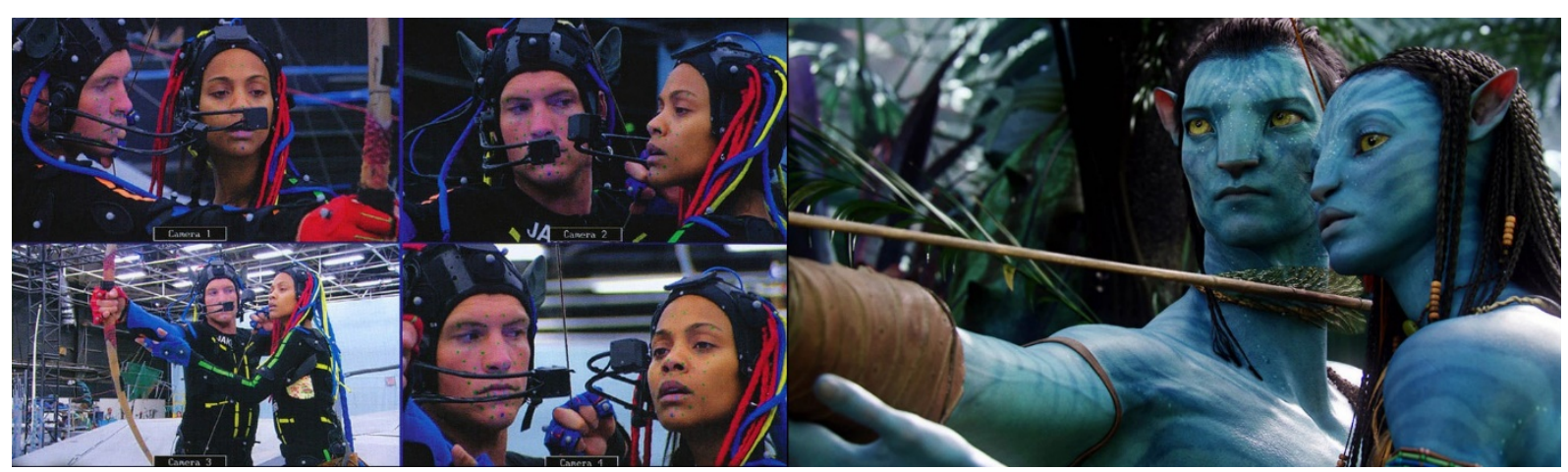

Figure 6. Motion capture production of Avatar (2009)

(Image from The Creative Arts \& Technology. http://cat-bc.wikia.com)

Table 1. List of films that utilized keyframe and motion capture technique

\begin{tabular}{|c|c|c|}
\hline Years & $\begin{array}{l}\text { Animation } \\
\text { Technique }\end{array}$ & Film Title \\
\hline \multirow[b]{2}{*}{ 1995 2017 } & Keyframe & $\begin{array}{l}\text { A Bug's Life, Captain Underpants: The First Epic Movie, Cars, Cars 2, Cars 3, Coco, Despicable Me 3, } \\
\text { Despicable Me, Ferdinan, Finding Dori, Finding Nemo, Frozen, How to Train Your Dragon, } \\
\text { Ice Age, Ice Age: Collision Course, Ice Age: Dawn of the Dinosaurs, Ice Age: The Meltdown, Inside Out, } \\
\text { Kung Fu Panda,Kung Fu Panda 2, Kung Fu Panda 3, Moana, Monster Inc., Monsters University, } \\
\text { Ratatouille, Rio, Rio 2, Robots, Shrek, Shrek 2, Shrek the Third, Shrek Forever After, Smurfs: The Lost } \\
\text { Village, Storks, The Incredibles, The Lego Batman Movie, The Lego Ninjago Movie, Toy Story, Toy Story } \\
\text { 2, Toy Story 3, Up, Wall-E, Zootopia }\end{array}$ \\
\hline & $\begin{array}{l}\text { Motion } \\
\text { Capture }\end{array}$ & $\begin{array}{l}\text { A Christmas Carol, Alice in Wonderland, Alice Through the Looking Glass, Ant-Man and the Wasp, Ant- } \\
\text { Man, Avatar, Avengers: Age of Ultron, Avengers: Infinity War, Batman v Superman: Dawn of Justice, } \\
\text { Beauty and the Beast, Captain America: Civil War, Dawn of the Planet of the Apes, Deadpool, Doctor } \\
\text { Strange, Final Fantasy: The Spirits Within, Gladiator, Guardians of the Galaxy, Guardians of the Galaxy } \\
\text { Vol. 2, Guardians, Happy Feet, Happy Feet 2, Hulk, I, Robot, Iron Man, Iron Man 2, Iron Man 3, Jurassic } \\
\text { World, King Kong, Man of Steel, Miss Peregrine's Home for Peculiar Children, Monster House, Night at } \\
\text { the Museum, Night at the Museum: Battle of the Smithsonian, Night at the Museum: Secret of the } \\
\text { Tomb, Pirates of the Caribbean: Dead Man's Chest, Pirates of the Caribbean: The Curse of the Black } \\
\text { Pearl, Rise of the Planet of the Apes, Snow White and the Huntsman, Spider-Man, Spider-Man 2, } \\
\text { Spider-Man 3, Spider-Man: Homecoming, Star Wars: The Force Awakens, Star Wars: The Last Jedi, } \\
\text { Tarzan, Ted, Ted 2, Teenage Mutant Ninja Turtles, Teenage Mutant Ninja Turtles: Out of the Shadows, } \\
\text { Terminator Genisys, Terminator 3: Rise of the Machines, The Adventures of Tintin, The Amazing Spider- } \\
\text { Man 2, The Avengers, The BFG, The Hobbit: An Unexpected Journey, The Hobbit: The Battle of the Five } \\
\text { Armies, The Hobbit: The Desolation of Smaug, The Incredible Hulk, The Jungle Book, The Legend of } \\
\text { Tarzan, The Lord of the Rings: The Fellowship of the Ring, The Lord of the Rings: The Return of the King, } \\
\text { The Lord of the Rings: The Two Towers, The Mummy, The Polar Express, Thor, Thor: Ragnarok, Thor: The } \\
\text { Dark World, Titanic, Transformers: The Last Knight, Tron: Legacy, War for the Planet of the Apes, } \\
\text { Warcraft: The Beginning, Wonder Woman }\end{array}$ \\
\hline
\end{tabular}

The increasing number of motion capture films indicates that not only the technology is improved, but also the performance is skilled. The most famous motion capture character is Gollum, also known as Smeagol, in 'The Lord of the Rings' (Figure 7). Andy Serkis performed as Gollum who expressed animated characters with the real human touch. It is the actor's physical movement and inner personality revealed in the digital character that attract the audience (Serkis, 2003). Andy Serkis acted out Gollum so vividly with personality that he was called as 'King of Motion Capture'.

From the case of digital character Gollum, we can understand that motion capture, although is replicate of human movement, can be as good as keyframe animation if the performing actor can act out the inner personality and subtle emotion. Therefore, the acting is actually the key factor that will affect the final result. Motion capture actors although are not shown in the screen, they put their acting in and thus embodiment of their work is shown. This concept is exactly same with animation production which animators are actors behind the scenes (Pixar).

Besides in the entertainment field, motion capture is also used in medical or sport research to analyze human's movement (Kageyama, Sugiyama, Kanehisa, \& Maeda, 2015; Mefferda \& Cordera, 2014); in behaviour science to study the relationships between people's behavior and violent games (Charles, Baker, Hartman, Easton, \& Kreuzberger, 2013); and in social science research to understand women's selection of men on the basis of body movement. These studies all take advantage of motion capture's characteristic of 'movement' recording and do 


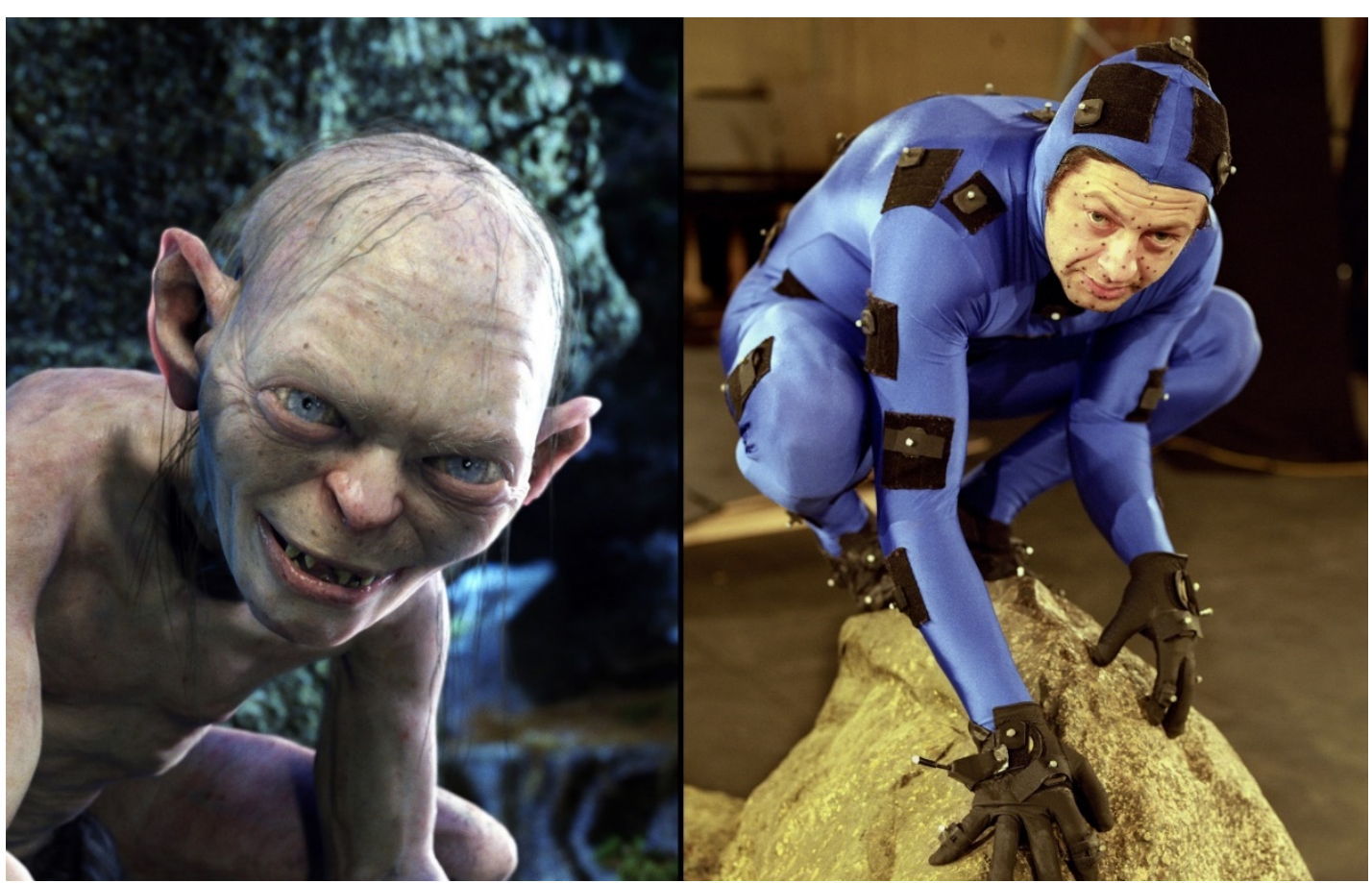

Figure 7. Gollum in 'The Lord of the Rings- The Two Towers' (2002)

(Image from Cinema News. http://www.cinemanews2.com.br)

further analysis. However, in animation field, besides production application, there are few further researches that use motion capture to investigate animation fundamental study. Motion capture can be integrated in education to assist learning and teaching. Through truly perform out the desired movements and emotions, students can observe their motion results with digital characters in real time and thus modify their acting for better outcome. We hope to take advantage of the real time visualization feature of motion capture to enhance character animation education. Hence, here in this study we utilize the tool to uncover whether students' creativity in motion design would be enhanced by motion capture.

\section{Creativity in Motion}

The design of animation has always emphasized the importance of creativity. From the pre-production stage of story design and character design, to production stage of animation design, these design aspects are the core essence of animation. An interesting story can bring audience into the plot and feel the tension or relaxation of the moments (Block, 2007; Glebas, 2008). Likewise, an attractive character design can express the character's personality and characteristics. With respect to the design of motion, both reality and creativity are considered important. On the one hand, the motions have to reveal reality in our cognitive human world; so the audience can accept the imaginary environment. On the other hand, the motions have to be reproduced to show certain 'unreal' in order to attract the audiences' eye. Here we can say that the unreal quality of motion is actually the creativity of motion. Character animation design has always emphasized on the appealing movement and surprising motion. The characters' motions have to present to a certain level that follows the law of physics; also, the motions have to show some features that will surprise or catch the audiences' attention. Therefore, creativity in motion takes a crucial part in character animation.

Creativity is often regarded as an inherent part of design process (Taura \& Nagai, 2011). Thus, in design pedagogy it is often assumed to be included in teaching to raise students' interests and motivation. Nevertheless, the meaning and definition of creativity is not well understood by teachers (Morgan, Dunn, Parry, \& O'Reilly, 2004). It is necessary for teachers to have a concise definition of creativity in particular task or project, so students could have a clear vision of their learning activity. And teachers can also have an objective framework to assess students' performance.

Studies on creativity was established by several researchers. J. P. Guilford is one of the important researchers in the field of creativity. He identified two distinct forms of thinking: divergent thinking and convergent thinking (Guilford, 1967). He stated that creativity was generation of ideas that were novel and appropriate to the field (Guilford, 1950). Divergent thinking is related to creative thoughts, or the ability to initiate unique and numerous answers to open-ended questions, while convergent thinking infers searching for a single, correct solution to a 
problem. Consequently, divergent thinking is often regarded as a synonym for creativity. Guilford operationally defined creativity through four major factors, i.e., originality, fluency, flexibility and elaboration, which were later put into practice by Ellis Paul Torrance (E Paul Torrance \& Aliotti, 1969) to assess individual creativity. Based on Guilford's creativity definition, Torrance developed a creativity test called 'Torrance Test of Creative Thinking' (TTCT) to measure divergent thinking and problem solving skills (E. P. Torrance, 1974, 1984). The TTCT task is conducted in a fixed time to evaluate the four creative factors expressed in the participant's responses. The definition of each scored factor is explained below.

(1) Originality: statistical uncommonness of total responses

(2) Fluency: quantity of appropriate responses

(3) Flexibility: quantity of different categories of relevant responses

(4) Elaboration: amount of detail in the responses

Many researchers had utilized the concept of TTCT to assess creativity in different domains (Rudowicz, Lok, \& Kitto, 1995; Runco, Millar, Acar, \& Cramond, 2010; Jing-Jyi Wu, 1998). Gardner indicated that creativity could reveal in various forms in divergent fields (Gardner, 2000). From his 'multiple intelligence' point of view, expression of creativity has to be evaluated with different ways according to the particular domain. Therefore, an actor's creativity cannot be assessed same as a dancer's. Creativity in body movement could have distinct forms in each area (Jing-jyi $\mathrm{Wu}, 2002)$. Based on this concept, the design of character animation is a form of creativity as well. The assessment of creativity has to correspond with motion design from the perspective of character animation. Animators have to propose various action designs and explore the possibilities of actions in order to decide an appropriate movement. It is through this divergent thinking of distinct designs of motions, animators' creativity is revealed in the works. Hence, in our research, in order to evaluate properly in character animation design, we mapped out our measure index of motion creativity to conform to each corresponding creative factor.

\section{RESEARCH DESIGN}

\section{Participants}

50 college students from animation department joined this experiment. Participants all had 2 years of animation training in their curriculum and their previous academic performances were $\mathrm{B}+$ in average. They were assigned to test group or control group randomly for avoidance of bias. Test group was equipped with the motion capture system while control group had to design motion from computer keyframe technique. Since they all had fundamental animation knowledge in prior learning experiences, for example, motion knowledge, observation and acting which are all related to creativity, no other information or advice on motion design was provided before the experiment. Besides, because the aim of this study was to discover whether students' creativity in animation design would be enhanced by motion capture, extra supportive materials would influence the results. Nevertheless, all participants were explained about requirement of each creativity factor, so they could think and create body motions without confusion.

\section{Measurement}

Their experimental results, that is, body motion design, were evaluated by 3 experts from the animation industry. Three creativity factors were examined. The first factor is originality, which we examined how participants could create uncommon motion design. Animators have to create poses that will distinguish the character from other characters. This is to show the "uniqueness and personality" of the individual character. This can be matched to the factor of originality. Animators also have to design various poses to show how the character act in different situations. This development of different ideas and selection of "appropriate motions" practically matches the second factor of fluency. The third factor is flexibility, which we examined the proportion of emotion design in the total appropriate motions. We set "sentiment ratio" to match flexibility factor since a certain motion design can be expressed in various states. For example, a walk can be a sneaky walk or an angry walk (Figure 8). Moreover, since we used keyframe and motion capture to design movements, their production feature differences would affect the quantity of emotions. Therefore, by calculating the sentiment ratio would be more reasonable to represent the results. Elaboration implies amount of detail in the responses. Nevertheless, elaboration factor is not included in our study though, because compared with motion capture, traditional keyframe animation requires huge amount of time to create detailed facial and body animation. Moreover, the motion capture system we used in this study did not capture facial expression either. Therefore, we excluded elaboration factor in our research to avoid unequal comparison. Figure 9 illustrates the corresponding relationship between creativity and character animation design. 


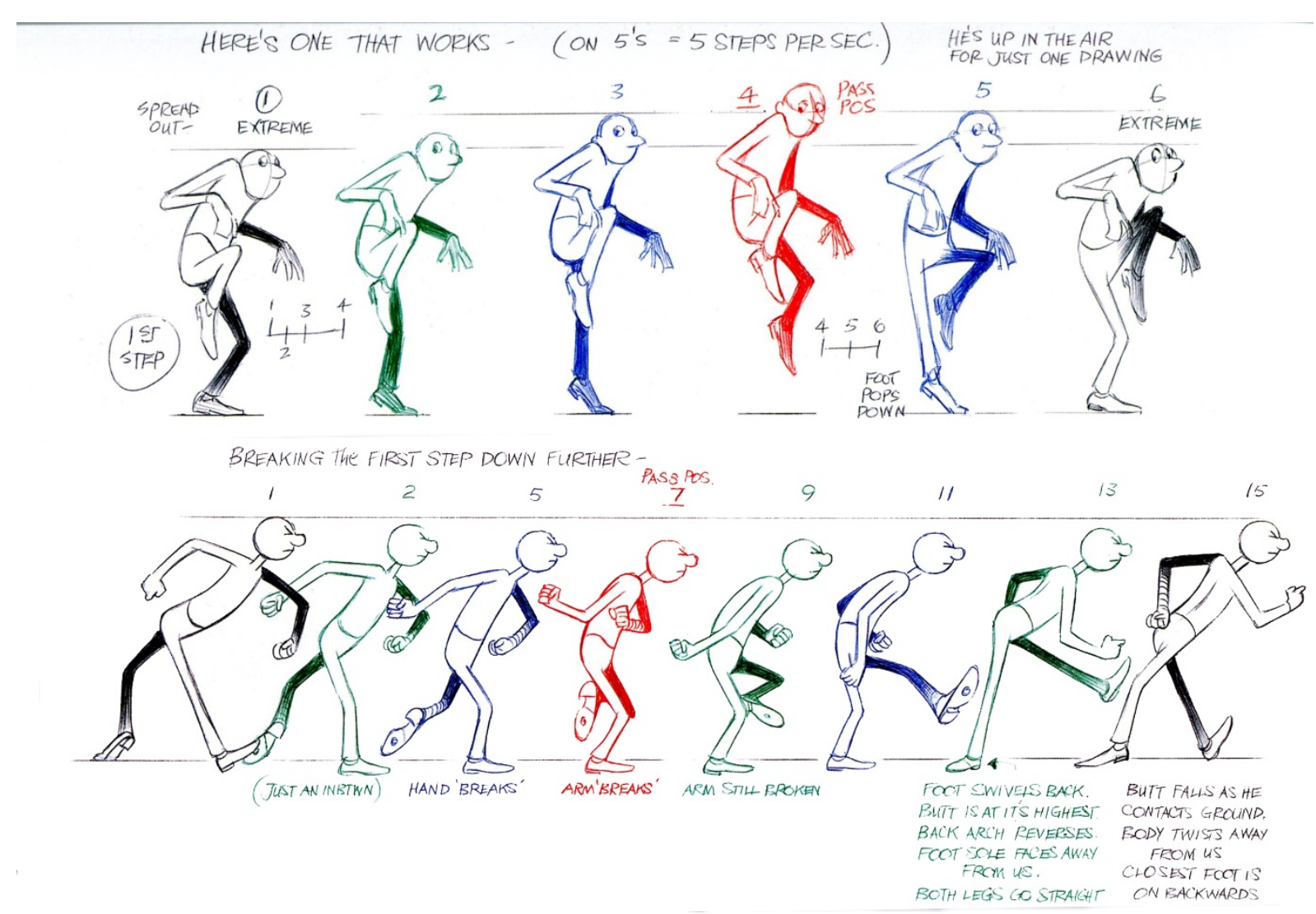

Figure 8. Walk with different emotions

(Image from The Animator's Survival Kit)

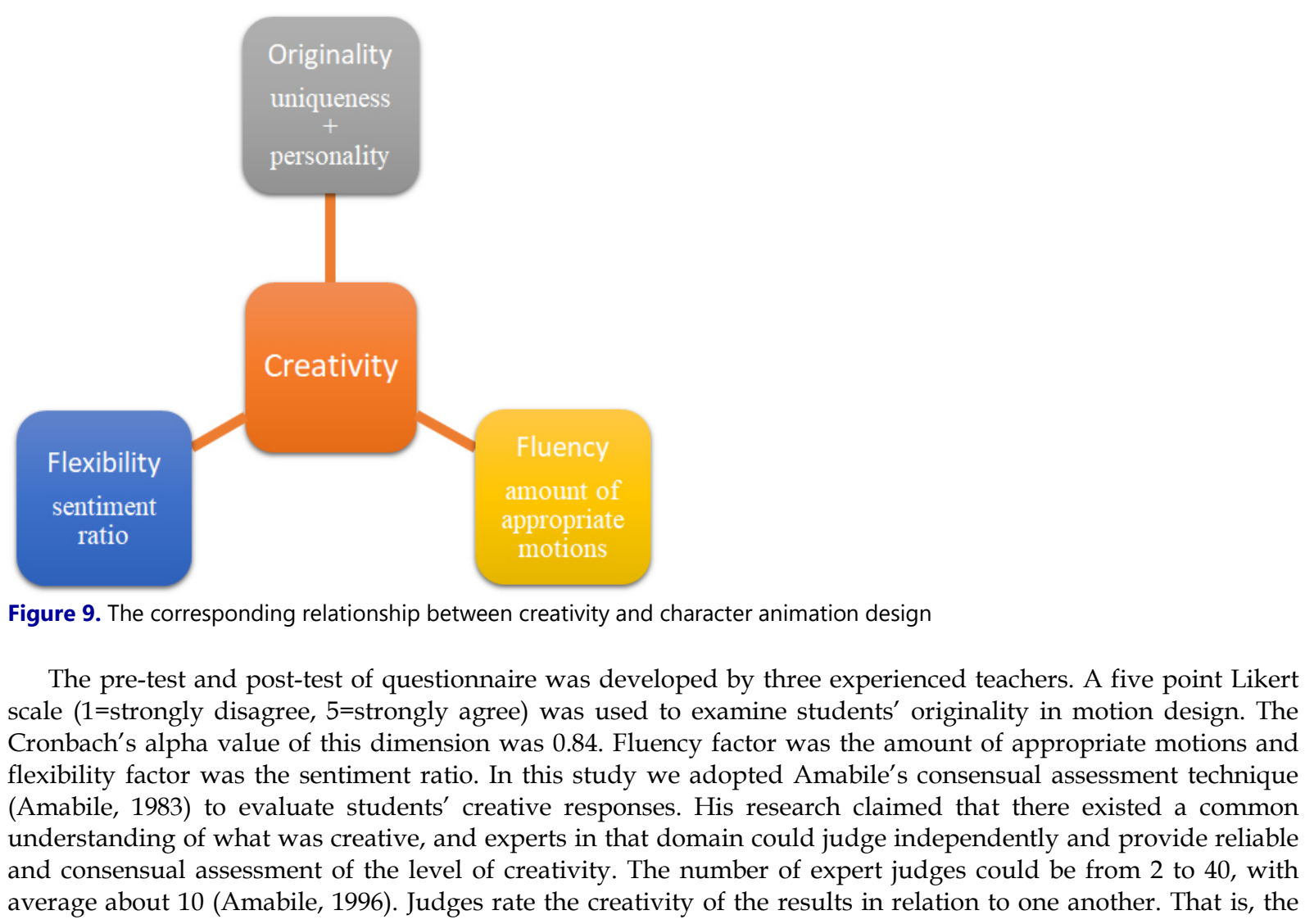




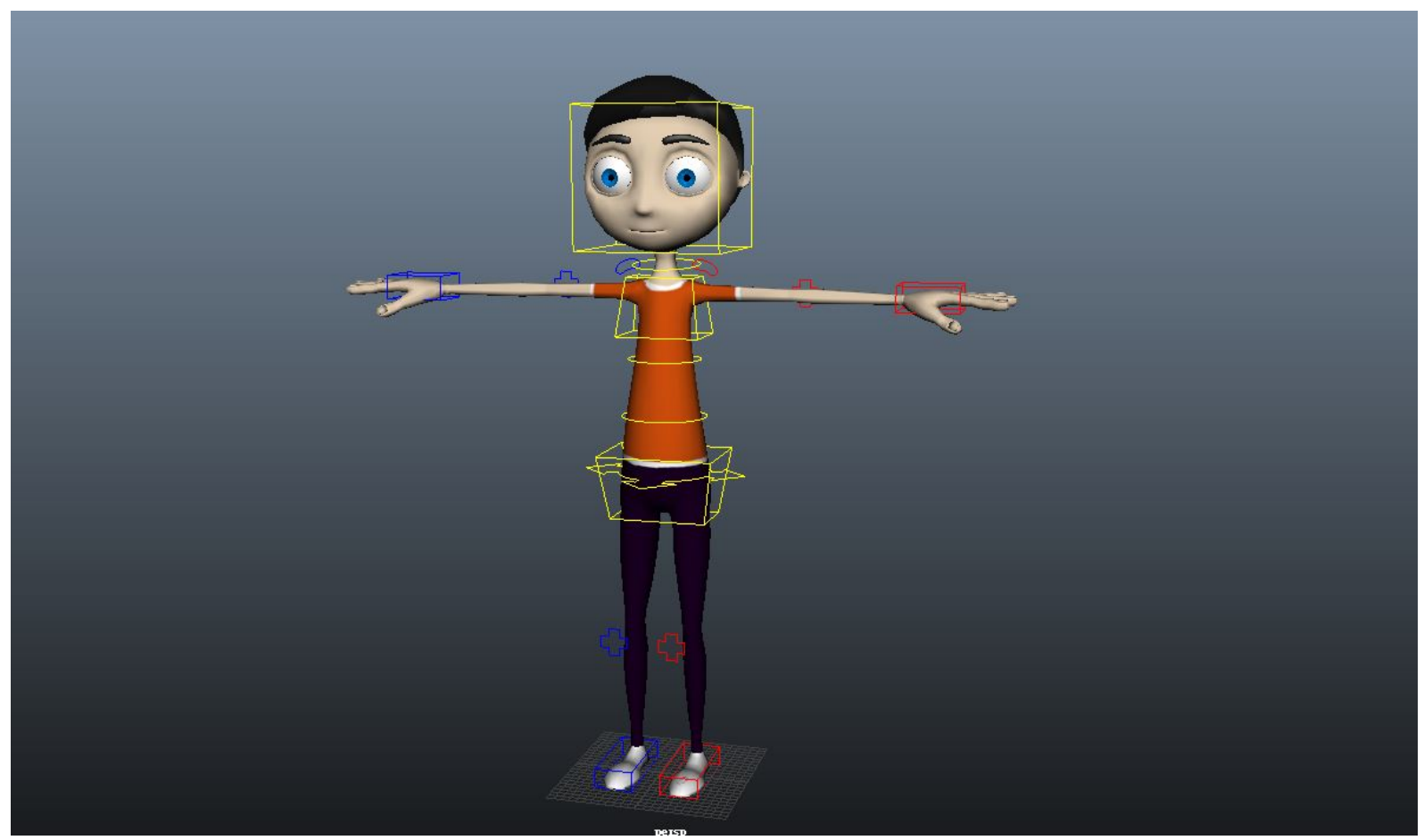

Figure 10. 3D character for motion design

ratings are comparative creativity of the things being judged. Many researches and industries have adopted this technique to evaluate creative designs/products/responses (Baer, 2003; Baer \& McKool, 2009; Hennessey, 1994). For example, Chen et al. in their cross-cultural examination of creative geometric shapes drawings found high consensus between European American and Chinese judges (Chen et al., 2002). In study of creative writing, researcher also found very high levels of inter-rater reliability (Baer, Kaufman, \& Gentile, 2004). Many other studies also have generally reported high inter-rater reliabilities in the 0.70 to 0.90 range among judges (Conti, Coon, \& Amabile, 1996; Hennessey, 1994; Kaufman, Baer, Cole, \& Sexton*, 2008).

T-test analysis was conducted to examine the differences between test group and control group. Interviews were also conducted with the participants afterwards to acquire qualitative data. The interview questions were designed to acquire participants' overall experiences with different methods (motion capture or keyframe), their thinking towards designing creative poses (originality factor), exploring different poses (fluency factor) and creating various emotional poses (flexibility factor). The interviews were recorded for later analysis. Content analysis method was applied to analyze participants' responses in context of interview questions. Two experienced teachers coded the same text to ensure consistent of judgement. The inter-coder reliability of an interview sample was 0.91 .

\section{Design Task}

Participants were asked to create interesting "walks" with the assigned digital character. The smoothness of movement or quality of the motion were not taken into consideration in this experiment, since we only examine the creativity of the motion design. The index for experts to judge creativity are uniqueness and personality (originality), amount of appropriate motions (fluency), and sentiment ratio (flexibility). Participants were provided with a digital animate-ready character to design body motions (Figure 10). There were 17 controllers (color boxes in Figure 10) on the character's main joints for control group to play with. As for test group, the design of body motion would be driven by 17 sensors of the motion capture system. Before the task, they were explained about the research goal of animation design creativity. Participants were encouraged to explore any possible motions as they desired. Information provided to the participants are listed as the following points.

- Motion task: interesting walk(s)

- Character: a digital animate-ready 3D character

Participants were required to finish the design task within 60 minutes. This task was conducted individually and followed by an interview when they finished the experiment. 

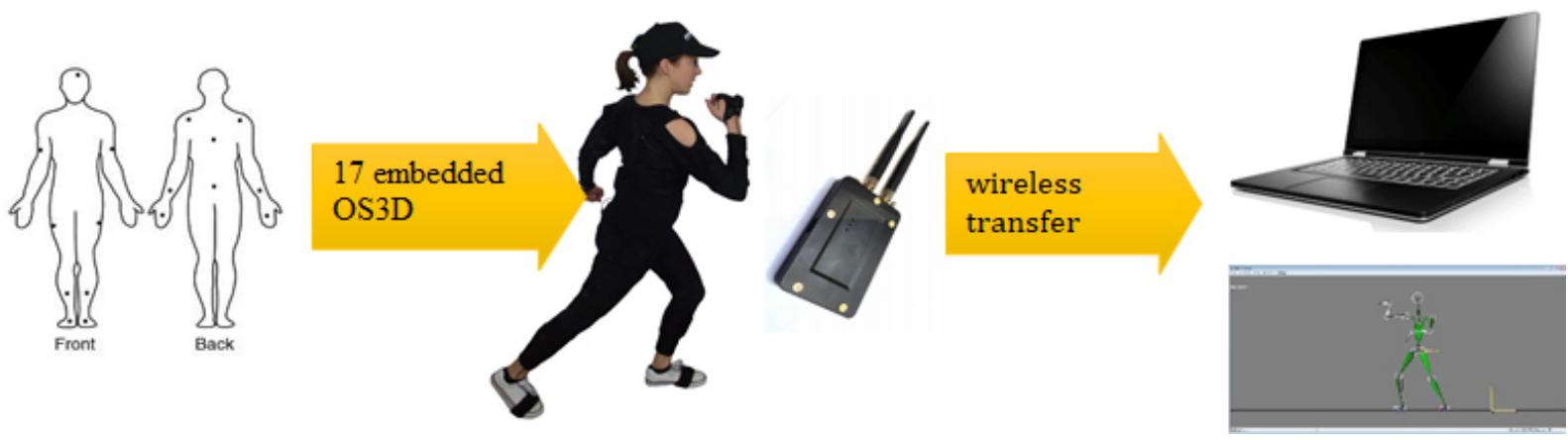

Figure 11. Structure and Interface of Animazoo IGS-180 System

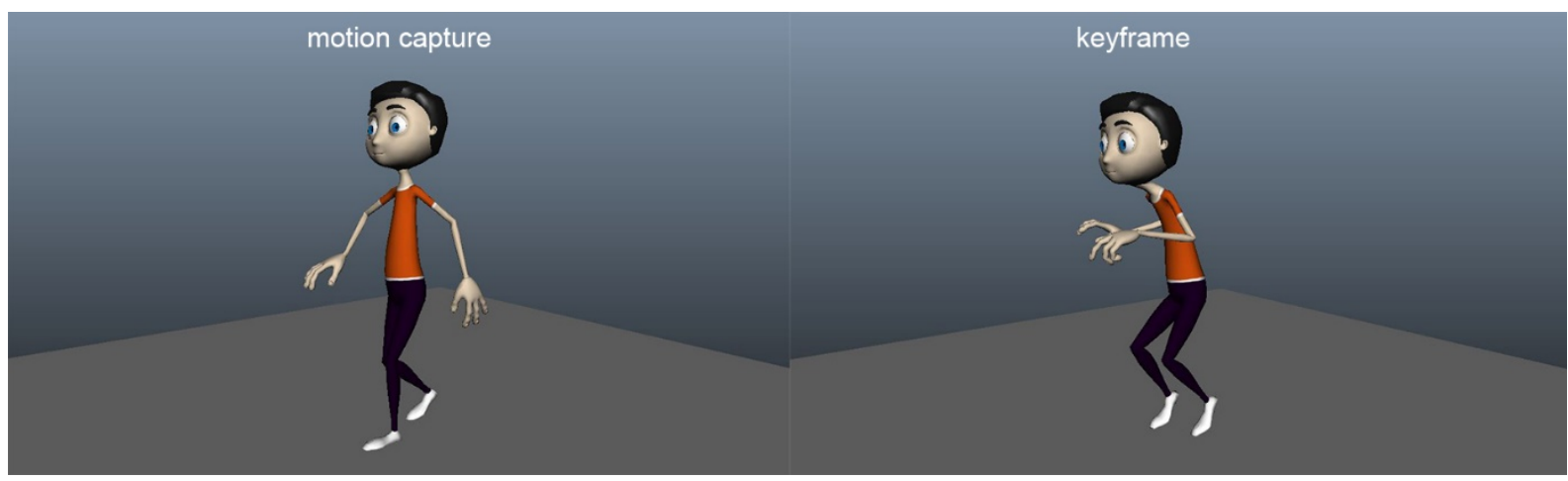

Figure 12. Motion poses from keyframe and motion capture

\section{Motion Capture System}

The motion capture system that we used in this study was Animazoo IGS-180. It is a wearable and portable Gyroscopes type of motion capture system. The system consists of 17 OS3D miniature orientation sensors which is suitable to detect and record the actor's body motion. The sensors are located in human's main joints and head to represent and record the actor's body motions. Each of the sensor is composed of tri-axial MEMS Gyroscopes, triaxial MEMS Accelerometers, and tri-axial magneto-resistive Magnetometers. The OS3D has onboard processor and embedded orientation algorithms that can allow direct transmission of motion data wirelessly and show in the system interface. Figure 11 shows the basic structure and interface of the Animazoo IGS-180 MOCAP system. Participants in the test group were trained on how to use the system to achieve their desired animation movement before the task.

\section{RESULTS}

\section{Creativity in Motion Design}

In the uniqueness and personality index, test group $(n=25)$ had average score of 2.76 while control group $(n=25)$ was 3.52. The standard deviation of the score was 0.59 and 0.50 for test and control group respectively. There was significant difference $(p=0.009<0.05)$ between two groups. This result implies that traditional keyframe method has better support for participants to express their creativity in the originality aspect. The reason for motion capture to have lower score could because of its real acting from participants. Since students are not trained actors, it is possible that they tended to act normally or naturally without overacting of the motion. Figure 12 shows an example of creative and less creative pose by keyframe and motion capture respectively. As we can see, keyframe showed asymmetry pose which is more interesting and creative, while motion capture pose revealed simple but dull pose. This phenomenon could because students' acting for the acting's sake without deep thinking of motion' purpose.

With regard to the amount of appropriate motions index, test group had in average 12.72 motions created and control group had 5.68 motions instead. Motion capture had obviously a lot more valid actions created than keyframe method. This phenomenon could because motion capture has the characteristic of instant recording of human's motion, while keyframe is manually set through rigging controller. Thus, in a same period of time, participants could create more motions with motion capture than with keyframe. This implies that motion capture has positive support for fluency element of creativity. Participants' fluency part of creativity could be enhanced through digital tool. 
In the sentiment ratio index, test group created average of 4.08 emotions and control group had 2.72 in average. The proportion of emotion design in the total appropriate amount were $32 \%$ and $48 \%$ respectively. The results were quite noteworthy. Motion capture although created more emotions in 60 minutes, in fact the sentiment ratio was lower than keyframe method. This implies that instant creation support from motion capture does not significantly enhance creativity in flexibility factor. Keyframe, although it requires manually set up and takes more time to accomplish a pose, this in fact assists animators to think thoroughly when designing a pose. Nevertheless, this preliminary result could possibly reflect only some facts. Further study should conduct with more participants and examine different tasks to verify the inference.

\section{Participants' Attitudes towards Motion Design}

After the motion design task, each participant was interviewed to understand his/her experience and attitude towards keyframe method or motion capture technology. Generally speaking, participants from test group who used motion capture, they indicated that motion capture was helpful for viewing what they did directly. It provided an intuitive way for them to "act out" the motion and see the result directly. Here we extracted some interviews from test group.

> Participant A: "The tool is easy to use and I can create any motions I have in my brain."

> Participant B: "It's good to see what I have done immediately and act out the motion directly without keyframing."

Another feature that participants responded towards motion capture was "time-saving" in motion design. Compared with keyframe method which participants had to manually set keys to pose proper movement, motion capture has the advantage of recording body movement instantly and thus save time in production. From their design results we can see that test group who used motion capture produced more motions than control group who created with traditional keyframe method. This phenomenon is also revealed in the interviews.

$>$ Participant C: "It is very easy to create motions in a short period of time. The tool is helpful to automatically save my actions and thus I can create more animations by only focusing on performance."

$>$ Participant D: "It is quite cumbersome to manually key each frame with the traditional method. It is difficult to achieve my desired motion in a short time."

The other positive point that participants mentioned about was the "fun and freedom" characteristic of motion capture. To see what they had done immediately was a special experience for participants. The instant recording provides a visual feedback of their performance. This feature could trigger participants' interests and thus could further encourage them to make any possible designs as they think of.

$>$ Participant E: “I've never thought of creating animation could be so fun. I enjoyed the process of motion design which I could explore any poses as I like."

$>$ Participant F: "The tool is very handy and convenient. I don't need to worry about setting keyframes."

Regardless of the positive feedback from most participants in test group, there are still few thinking about motion capture. Participants expressed that they were not comfortable to act out motions in front of others.

> Participant G: "The tool is very convenient, but it is quite embarrassing to wear the suit and perform in front of people."

$>$ Participant H: "I usually act out motions in a private place where no one can see me. I feel more comfortable when I try to create funny motions."

Regarding traditional keyframe method, some participants revealed that "extreme poses" could be achieved with keyframe. This response reflects what animators regard animation should contain, i.e., exaggeration (Williams, 2012). It is through over-acting of the movement that audiences could feel 3D character alive and vividness.

$>$ Participant I: "Posing the character in an extreme way makes him more vivacious. This is what virtual character should contain in its pose."

$>$ Participant J: "One good thing about keyframe is its offer of flexible skeleton that I could manipulate with. I don't need to worry about breaking bones or unable to set extreme poses."

Control group also revealed that they tended to spend more time on modifying poses than creating new design. This reflects the result of fewer emotions in keyframe method.

$>$ Participant K: "When in design of motions with keyframe method, I tended to focus on polishing current pose instead of exploring new possibility."

$>$ Participant L: "Although I know we are encouraged to create different movements in a certain time period, the manipulating way that keyframe method inherent makes me staying in current design." 


\section{DISCUSSIONS}

\section{Creativity in Animation Education}

Creativity in animation design is always an important point. Virtual characters' motion design can be achieved through traditional keyframe and motion capture technology. In this research, we found that keyframe method was helpful in uniqueness and personality of action, which implied originality element in creativity was revealed. Motion capture, on the other hand, was more supportive in fluency factor in creativity. Digital tool such as motion capture can increase motion designs in quantity. Both are also key components of creativity. With regard to the flexibility factor, we found that although motion capture could create more emotions in amount, keyframe method actually offer higher proportion of sentiment design. Therefore, to develop students' creativity in character animation design, it is suggested to utilize the combination of both methods in teaching. By using keyframe's exaggeration feature, we could guide students to understand animation design aesthetics which is the fundamental knowledge. With the help of motion capture technology, we could increase students' interests and motivations in learning, and further explore more possible motion designs.

We shall further understand that animation education is not only skills and knowledge learning, but also is creative ability training. Educators shall pay attention to the question of how to enhance students' creativity (Guyotte, Sochacka, Costantino, Walther, \& Kellam, 2014; Hargrove, 2012). Therefore, with the fundamental ability strengthened, it could support other transdisciplinary learning. Students' divergent ideas and thinking could be a nourishing source in character animation design. Hence, educators in animation should dedicate to develop students' creativity since creativity can be fostered through appropriate teaching (Clinton \& Hokanson, 2012; Fasko, 2001). Various techniques have been proposed to promote creativity. Nickerson (Nickerson, 1999) in his research summarized approaches that are used by academia and industry. Educators and leaders play a key role in guiding students or employees (Hargrove, 2012). By adopting appropriate methods, they can help students or employees to discover more opportunities, acquire specific knowledge, stimulate explorations, and build up confidence. These techniques can be applied to various subjects or professions (Clinton \& Hokanson, 2012; Zhou, 2012). More importantly, the approaches are not only general concepts, but also incorporating proper tools or teaching aids to stimulate creativity (Burnard, 2007; Ohler, 2008). This idea can further apply to animation education, especially character animation. By adding in new teaching tool, teachers can explain and demonstrate motions in design. Motion capture is one of the tools that can be very beneficial to teaching and learning of character animation. Also, it is worth noting that in Nickerson's compilation of creativity techniques, 'building basic skills' can be helpful to creativity as well. To maser in character animation, it relies mostly on practice and hands on training. Therefore, through the actual acting implementation with motion capture technology, students can acquire both skills and knowledge of character animation design.

\section{Combination of Old and New}

The training of character animation takes a long time to cultivate an excellent animator. Traditional training methods include sense of timing, keen observation, aesthetics, acting, and lots of practice as we have discussed. It is necessary to establish solid foundation with traditional training in order to build up an animator with animation literacy. However, to advance students in character animation design, it is important to bring creativity into teaching and learning process. There are several ways to promote creativity in education, such as building basic skills, stimulating exploration, providing opportunities for discovery, and incorporating proper tools (Nickerson, 1999). These techniques could actually be adopted in animation teaching through motion capture. There are several advantages to combine motion capture with traditional training. First, students can acquire digital ability which is a basic skill in 3D character animation. Second, because motion capture has feature of instant motion preview, students can see their performance and adjust for better acting. Third, motion capture can enhance creativity in students. Since character animation design needs to show uniqueness and personality, which is originality factor of creativity, motion capture can support this by recording actors' unique performances for further analysis. Also, with the prompt record of movement, students can perform as many different motions as possible to explore possible designs. This feature of motion capture is corresponding with fluency factor of creativity. Forth, through acting out the motions or poses, students can practically understand motion knowledge, physics, and anatomy. Motion capture can be helpful in conveying domain knowledge with intuitive implantation. Therefore, it is highly recommended to combine traditional keyframe animation training with motion capture application in character animation education. This new teaching practice can not only enhance students' creativity but also include fundamental animation literacy in learning. 


\section{CONCLUSIONS}

The learning process of character animation is diverse and transdisciplinary. It requires time, efforts, and creativity to master in motion design. Traditional training methods can contribute more in sense of timing, acting and aesthetics which are fundamental abilities of character animation. However, design of motion also requires digital ability, creativity and motion knowledge. These aspects of ability can be acquired through the utilization of motion capture technology. With the assistance of motion capture, students can see how their acting being transformed into digital character and can further explore more motions or modify their acting performance. This unique feature of motion capture is helpful in stimulating creativity of students. Incorporating technology into teaching and learning is an irresistible trend in education (Gibson, 2010). For teachers, it can help to demonstrate conceptual knowledge with visualization. Also, it can afford opportunity for prompt creation, which is an indispensable element in design. For students, the use of digital tool can not only train their technical familiarity, but also advance their creativity. Animation design is a field that requires skills, knowledge, and last but not least, creativity. It is suggested that teachers in animation field can adopt proper digital tools to assist their teaching for better learning outcomes. Motion capture can be a great tool for character animation design. Likewise, other animation professions could need different tools. Further research could be on the design process of motion design, to investigate how keyframe/motion capture could assist teachers and students in the teaching and learning feedback. Thus, we could utilize digital tool in a more effective way. No matter which tool or technique is used, it is educators' mission to cultivate future talents with broad perspective and vision.

\section{REFERENCES}

Amabile, T. M. (1983). The social psychology of creativity: A componential conceptualization. Journal of personality and social psychology, 45(2), 357. https:/ / doi.org/10.1037/0022-3514.45.2.357

Amabile, T. M. (1996). Creativity in context: Update to the social psychology of creativity: Hachette UK.

Baer, J. (2003). The impact of the core knowledge curriculum on creativity. Creativity Research Journal, 15(2-3), 297300. https:// doi.org/10.1080/10400419.2003.9651422

Baer, J., \& McKool, S. S. (2009). Assessing creativity using the consensual assessment technique. In Handbook of research on assessment technologies, methods, and applications in higher education (pp. 65-77): IGI Global. https:/ / doi.org/10.4018/978-1-60566-667-9.ch004

Baer, J., Kaufman, J. C., \& Gentile, C. A. (2004). Extension of the consensual assessment technique to nonparallel creative products. Creativity Research Journal, 16(1), 113-117. https:/ / doi.org/10.1207/s15326934crj1601_11

Block, B. (2007). The Visual Story: Creating the Visual Structure of Film, TV and Digital Media (Second Edition ed.). New York: Focal Press.

Burnard, P. (2007). Reframing creativity and technology: Promoting pedagogic change in music education. Journal of Music, Technology E Education, 1(1), 37-55. https:/ / doi.org/10.1386/jmte.1.1.37_1

Charles, E. P., Baker, C. M., Hartman, K., Easton, B. P., \& Kreuzberger, C. (2013). Motion capture controls negate the violent video-game effect. Computers in Human Behavior, 29, 2519-2523. https:/ / doi.org/10.1016/j.chb.2013.05.028

Chen, C., Kasof, J., Himsel, A. J., Greenberger, E., Dong, Q., \& Xue, G. (2002). Creativity in drawings of geometric shapes: A cross-cultural examination with the consensual assessment technique. Journal of Cross-Cultural Psychology, 33(2), 171-187. https:/ / doi.org/10.1177/0022022102033002004

Clinton, G., \& Hokanson, B. (2012). Creativity in the training and practice of instructional designers: the Design/Creativity Loops model. Educational Technology Research and Development, 60(1), 111-130. https:/ / doi.org/10.1007/s11423-011-9216-3

Conti, R., Coon, H., \& Amabile, T. M. (1996). Evidence to support the componential model of creativity: Secondary analyses of three studies. Creativity Research Journal, 9(4), 385-389. https://doi.org/10.1207/s15326934crj0904_9

Costantino, T. (2017). STEAM by another name: Transdisciplinary practice in art and design education. Arts Education Policy Review, 1-7. https:/ / doi.org/10.1080/10632913.2017.1292973

Deja, A. (2015). The Nine Old Men: Lessons, Techniques, and Inspiration from Disney's Great Animators: Focal Press. https://doi.org/10.4324/9780203756614

Delbridge, M. (2016). Why motion capture performances deserve an Oscar. Retrieved from https:/ / theconversation.com/why-motion-capture-performances-deserve-an-oscar-67138

Dent, S. (2014). What you need to know about 3D motion capture. Retrieved from http:/ / www.engadget.com/2014/07/14/motion-capture-explainer/ 
Fasko, D. (2001). Education and Creativity. Creativity Research Journal, 13(3 \& 4), 317-327. https://doi.org/10.1207/S15326934CRJ1334_09

Freedman, Y. (2012). Is It Real ... or Is It Motion Capture? The Battle to Redefine Animation in the Age of Digital Performance. The Velvet Light Trap, 69, 38-49. https:/ / doi.org/10.1353/vlt.2012.0001

Gardner, H. E. (2000). Intelligence reframed: Multiple intelligences for the 21st century: Hachette UK.

Gibson, R. (2010). The 'art' of creative teaching: implications for higher education. Teaching in Higher Education, 15(5), 607-613. https: / / doi.org/10.1080/13562517.2010.493349

Glebas, F. (2008). Directing the Story: Professional Storytelling and Storyboarding Techniques for Live Action and Animation. Burlington: Focal Press.

Guilford, J. P. (1950). Creativity. American psychologist, 5, 444-454. https:/ / doi.org/10.1037/h0063487

Guilford, J. P. (1967). The Nature of Human Intelligence: McGraw-Hill.

Guyotte, K. W., Sochacka, N. W., Costantino, T. E., Walther, J., \& Kellam, N. N. (2014). Steam as Social Practice: Cultivating Creativity in Transdisciplinary Spaces. Art Education, 67(6), 12-19. doi:10.1080/00043125.2014.11519293

Hargrove, R. (2012). Fostering creativity in the design studio: A framework towards effective pedagogical practices. Art, Design E Communication in Higher Education, 10(1), 7-31. https:/ / doi.org/10.1386/adch.10.1.7_1

Hennessey, B. A. (1994). The consensual assessment technique: An examination of the relationship between ratings of product and process creativity. Creativity Research Journal, 7(2), 193-208. https:/ / doi.org/10.1080/10400419409534524

Johnston, O., \& Thomas, F. (1981). Disney Animation: The Illusion of Life: Abbeville Press.

Kageyama, M., Sugiyama, T., Kanehisa, H., \& Maeda, A. (2015). Difference between Adolescent and Collegiate Baseball Pitchers in the Kinematics and Kinetics of the Lower Limbs and Trunk during Pitching Motion. Journal of Sports Science and Medicine, 14, 246-255.

Kaufman, J. C., Baer, J., Cole, J. C., \& Sexton*, J. D. (2008). A comparison of expert and nonexpert raters using the consensual assessment technique. Creativity Research Journal, 20(2), 171-178. https:/ / doi.org/10.1080/10400410802059929

Liao, C. (2016). From Interdisciplinary to Transdisciplinary: An Arts-Integrated Approach to STEAM Education. Art Education, 69(6), 44-49. https:/ / doi.org/10.1080/00043125.2016.1224873

Mefferda, A. S., \& Cordera, E. E. (2014). Assessing Articulatory Speed Performance as a Potential Factor of Slowed Speech in Older Adults. Journal of Speech, Language, and Hearing Research, 57, 347-360. https:/ / doi.org/10.1044/2014_JSLHR-S-12-0261

Menache, A. (2010). Understanding Motion Capture for Computer Anitvation: Morgan Kaufmann.

Morgan, C., Dunn, L., Parry, S., \& O'Reilly, M. (2004). The student assessment handbook: new directions in traditional and online assessment. London: Routledge Falmer.

Mou, T.-Y., \& Tu, G.-S. (2013). Storyboarding for animation. Taipei: Grandtech.

Muybridge, E. (2012). Muybridge's Complete Human and Animal Locomotion (A. V. Mozley Ed.): Dover Publications.

Nickerson, R. S. (1999). Enhancing creativity. In R. Sternberg (Ed.), Handbook of Creativity: Cambridge University Press.

Ohler, J. (2008). Digital Storytelling in the Classroom: new media pathways to literacy, learning, and creativity. Thousand Oaks: Crowin Press.

Pixar. The Science Behind Pixar-Animation. Retrieved from http:/ / sciencebehindpixar.org/pipeline/animation

Riley, S. (2012). STEAM point: A guide to integrating science, technology, engineering, the arts, and mathematics through the common core (Vol. null).

Rudowicz, E., Lok, D., \& Kitto, J. (1995). Use of the torrance tests of creative thinking in an exploratory study of creativity in hong kong primary school children: A cross-cultural comparison. International Journal of Psychology, 30(4), 417-430. https:// doi.org/10.1080/00207599508246577

Runco, M. A., Millar, G., Acar, S., \& Cramond, B. (2010). Torrance Tests of Creative Thinking as Predictors of Personal and Public Achievement: A Fifty-Year Follow-Up. Creativity Research Journal, 22(4), 361-368. https:/ / doi.org/10.1080/10400419.2010.523393

Salomon, A. H. (2013). Growth In Performance Capture Helping Gaming Actors Weather Slump. Retrieved from https://www.backstage.com/news/spotlight/growth-performance-capture-helping-gaming-actorsweather-slump/

Serkis, A. (2003). Gollum: How We Made Movie Magic: Houghton Mifflin. 
Taura, T., \& Nagai, Y. (2011). Discussion on Direction of Design Creativity Research (Part 1) - New Definition of Design and Creativity: Beyond the Problem-Solving Paradigm. In T. Taura \& Y. Nagai (Eds.), Design Creativity 2010 (pp. 3-8). London: Springer London. https:/ / doi.org/10.1007/978-0-85729-224-7

Torrance, E. P. (1974). The Torrance Tests of Creative Thinking-Norms-Technical Manual Research Edition-Verbal Tests, Forms A and B- Figural Tests, Forms A and B. Princeton, NJ: Personnel Press.

Torrance, E. P. (1984). The Torrance Tests of Creative Thinking streamlined (revised) manual Figural A and B. Bensenville, IL: Scholastic Testing Service.

Torrance, E. P., \& Aliotti, N. C. (1969). Sex differences in levels of performance and test-retest reliability on the Torrance tests of creative thinking ability. The Journal of Creative Behavior, 3(1), 52-57. https:/ / doi.org/10.1002/j.2162-6057.1969.tb00044.x

Williams, R. (2012). The Animator's Survival Kit: A Manual of Methods, Principles and Formulas for Classical, Computer, Games, Stop Motion and Internet Animators. UK: Faber \& Faber.

Wu, J.-J. (1998). Handbook of Chinese version of Torrance Tests of Cretive Thinking.

$\mathrm{Wu}$, J.-j. (2002). Enticing the Crouching Tiger and Awakening the Hidden Dragon: Recognizing and Nurturing Creativity in Chinese Students. Research in Applied Psychology, 15, 17-42.

Zhou, C. (2012). Integrating creativity training into problem and project-based learning curriculum in engineering education. European Journal of Engineering Education, 37(5), 488-499. https:/ / doi.org/10.1080/03043797.2012.714357

\section{http://www.ejmste.com}

